\section{UNCLASSFFED 0}

OAK RIDGE NATIONAL LABORATORY

Ontrated by

UAION CARBIDE NUCLEAR COMPANY

\section{एटC}

POST OFFICE BOX $P$

OAK RIDGE, TENNESSEE

कातिक

DATE; December 28, 1956

sUBJECT: A Semf-Emplateal gyuation for Palr Production Below $5 \mathrm{Mev}$

TOi Distribution

Frow: C. D. Zerby and H. S, Woran

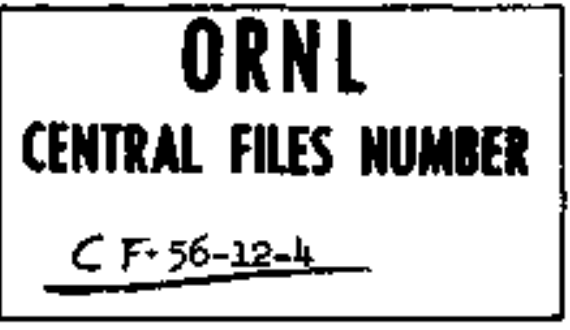

copr No. 10

Bxternel Dystribution Authorized

Distribution

1. E. P. Blizard

2. A. A. Charple

3. F. L. Keller

4. F. C. Maienschotn

5. B. B. Moren

6. R. B. Murray

7. R. W. Peelle

B. A. Bimon

9. C. D. Zerby

30-24. TISE, ABC हो]

25-26. Lab. Records

27. GRKL-RiC

This decument contains Information al a peoliminary noture and was arepared primarily for internal unt at the Oet Ridad National Leboratory, it is evbtect to ruviaion of carrection and therefore dote not ropriseant o finat report. 


\section{DISCLAIMER}

This report was prepared as an account of work sponsored by an agency of the United States Government. Neither the United States Government nor any agency Thereot, nor any of their employees, makes any warranty, express or implied, or assumes any legal liability or responsibility for the accuracy, completeness, or usefulness of any information, apparatus, product, or process disclosed, or represents that its use would not infringe privately owned rights. Reference herein to any specific commercial product, process, or service by trade name, trademark, manufacturer, or otherwise does not necessarily constitute or imply its endorsement, recommendation, or favoring by the United States Government or any agency thereof. The views and opinions of authors expressed herein do not necessarlly state or reflect those of the United States Government or any agency thereof. 


\section{DISCLAIMER}

Portions of this document may be illegible in electronic image products. Images are produced from the best available original document. 


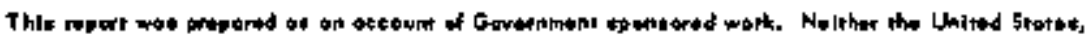

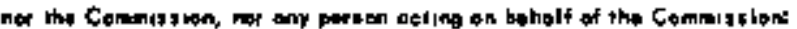

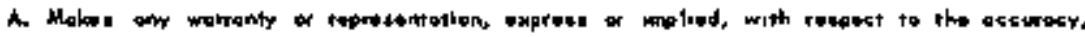

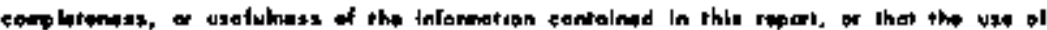

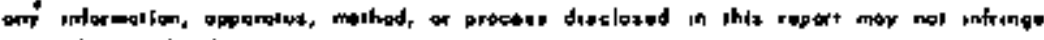
privetoly awned right, a

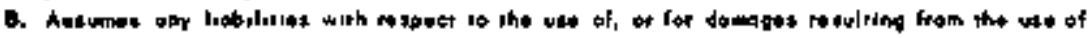

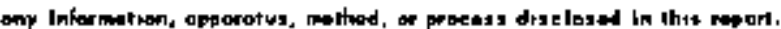

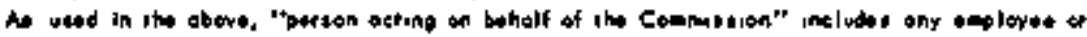

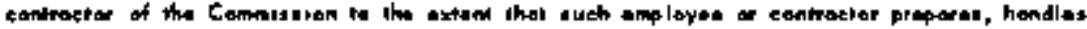

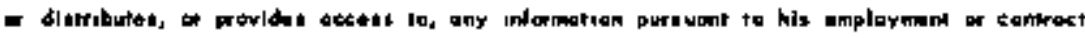
with the temmiseion.

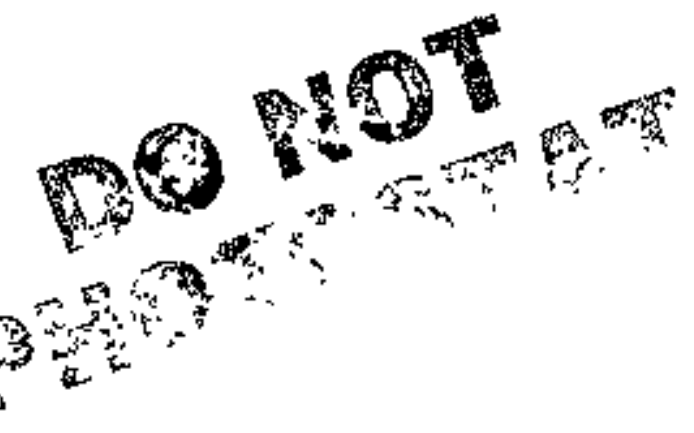




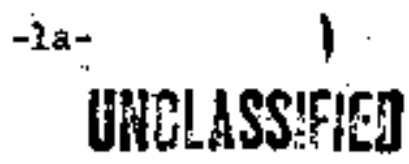

\section{A Sent- Fapirical gquation for Peir Froduction Below 5 Mev}

C. D. Zerby and H. S. Horan

It is well" known that there exists a afscrepsncy between experimental and theoretical Born approxtmation calculations of the cross section for production of electron-positron palrs by germis rays. The ratio of the cross section determined by experiment to that given by the Borm approximation Is greater than one at low gamma-ray energy and less than one at high gamma-ray energy. The crossover. occurs at approxtmately $6.5 \mathrm{~kg}$ as determined from the experiments of Rosenblum et al. 1

The discrepancy between experiment and theory has been reconctled in part by the work of Bethe end Marinon ${ }^{2}$ who determined the differential crose section at high energy using wave functions that closely approximate the correct wave functions. The Irtegral cross section given by Davses, Bethe, and Maximon ${ }^{3}$ compares quite well wth experimental values above 88 lev. In the region below 88 bov the solution of the wave equation using the correct wave functions has been done numerically for a few cages by Jaeger and HuIme. 4-6 Their results have been compared with experinent by

1. E. S. Rosenblun, E. F. Shroder, and R. M. Hazner, Jr., Fhys. Rev. 88, 612 (1952).

2. H. A. Betbe and I. C. Maximon (Part I), Phys. Rev. 93, 768 (1954):

3. H. Darieu, H. A. Bęthe, and L. C. Haxtmon, (Part II) Phys. Rev. 93, 788 (1954).

4. J. C. Jaeger and H. R. Hulme, Froce. Roy. Soc. (London) Al53, 443 (1936).

5. J. C. Jaeger, Nature 137, 781 (1936).

6. J. C. Jaeger, hature 148, 86 (19l1). 


\section{UACLASSFIEU}

$-2-$

several authord $1,7,8$ with good agreement. However, it is not easy to interpolete of extrapolate the numerical results to obtain the cross section for an arbitrary energy and element with charge $z$. This has lead several authors to suggest an empirteal correction to the Bethe-feitler (Born approxination) equation 9 based on experimental results.

The emptrical equations suggested by Dayton 7 to take care of the $z$ dependence were

$$
\begin{aligned}
& \sigma(\text { corrected })=\sigma(\operatorname{mon}) \times\left(1+1.59 \times 10^{-4} \mathrm{z}^{2}\right) \text { at } 1.33 \mathrm{Kev} \\
& \sigma(\text { corrected })=\sigma(\text { Born }) \times\left(1+3.39 \times 10^{-5} \mathrm{z}^{2}\right) \text { at } 2.62 \mathrm{Kev}
\end{aligned}
$$

where $\sigma$ is the cross : eection for peir production in the field of the nucleus and $\mathrm{z}$ is the etomic charge. The empirical dependence on energy can be obtained with the use of Eqa. (1) and (2) and the aditional information that Bethe-Fieitler equation matches experinent at approximately $6.5 \mathrm{Mev}{ }^{1}$ The proposed empirical equation becomes

$$
\begin{gathered}
\sigma(\text { corrected })=\sigma(\text { Born }) \times\left(1+7.824 \times 10^{-4} e^{-0.612 k} \mathrm{z}\right) \\
\text { for } 2<k<12
\end{gathered}
$$

where $k$ is the photon energy in untts of $m_{0} e^{2}$. The inequality linfting the upper energy bound of Eq. (3) comes from the exponential energy correction which does not go to zero at $6.5 \mathrm{Mev}$. The lower energy bound is not set equal to the threshold energy of $2 \mathrm{H}_{0} \mathrm{e}^{2}$ because of the uncertainty that

7. I. E. Dayton, Phys. Rev. 69, 544 (1953).

8. H. I. West, Jr, , Phys, Rev. 101, 915 (1956).

9. W, Reitler, The Quantum Theory of Radiation (Oxford University Press, 1944) p. 296. 


\section{WHGLASSIFEED}

such a simple empirical correction factor will apply. At $1.17 \mathrm{Kev}$. Indicated a correction term for the 2 dependence such as given in Bqs. (1) and (2) couid not be made to apply to the evailable data. It should be polnted out, however, that the pair-production cross section is only a small percentage of the total crass section in the energy range of $1.17 \mathrm{Nev}$ and below so the use of Iq. (3) down to an energy of $2 \mathrm{~m}_{\mathrm{o}} \mathrm{e}^{2}$ will introduce little error to the total cross section.

A simplified epproximation to the Bethe-Heitler differential cross section has been given by Hough ${ }^{10}$ wich 19 repeatod here with the empirical correction term given in $\mathrm{Bq}$. (3). The limita quoted on the equations are restricted by the empirical correction terms and do not necessarily indicate the restriction of application of Hough's approximation. The simplifled Aifferential cross section is

$\frac{\mathrm{d} \sigma}{\mathrm{d} \mathrm{E}_{+}}=\overline{\mathrm{d}} \mathrm{dy}\left[1+0.135(\mathrm{Q}-0.52) \mathrm{y}\left(1-\mathrm{y}^{2}\right)\right](\mathrm{k}-2)^{-1} \mathrm{~g} \quad$ for $2<\mathrm{k}<12$

where the second term in the brecket is dropped when it becomes negative (below $k=4.2$ ), and

$$
\begin{aligned}
& \beta=\left(1+7.824 \times 10^{-4} \mathrm{e}^{-0.612 \mathrm{k}} \mathrm{z}^{2}\right) \\
& \sigma=\text { cross section }\left(\mathrm{cm}^{2} / \mathrm{atom}\right) \\
& \mathbf{E}_{+}=\text {energy of the positron on } \mathrm{m}_{0} \mathrm{c}^{2} \text { units } \\
& x=\left(\mathrm{s}_{+}-1\right) /(\mathrm{k}-\mathrm{z}) \\
& \mathrm{y}=2[\mathrm{x}(1-\mathrm{x})] 1 / 2 \\
& \bar{\Phi}=\mathrm{z}^{2} / 137\left(\mathrm{e}^{2} / \mathrm{m}_{0} \mathrm{c}^{2}\right)^{2}
\end{aligned}
$$

10. P. V. C. Hough, Pnys. Rev. 73, 266 (2948). 


\section{UACLASSFFED}

$-4-$

The value of $Q$ is given by

$$
Q=(1-\gamma)\left[\frac{1}{3}\left(4-\gamma^{2}\right)(1-1)-\gamma^{2} \alpha(\alpha-1)-\gamma^{4} \alpha(1-\alpha)\right]
$$

where

$$
\begin{aligned}
& \gamma=\frac{2}{\mathrm{k}} \\
& \mathrm{L}=\left[\frac{2}{\left(1-\gamma^{2}\right)} \ln \left(\frac{\mathrm{k}}{2}\right)\right] \\
& \alpha=\frac{1}{(1-\gamma)^{1 / 2}} \ln \left[\left(\frac{\mathrm{k}}{2}\right)+\left(\frac{\mathrm{k}^{2}}{4}-1\right)^{1 / 2}\right]
\end{aligned}
$$

Integretion of $\mathrm{Eq}$. (4) over the range of $\mathrm{E}_{+}$from 1 to $\mathrm{k}$ - 1 givea the total eross section

$\sigma$ (corrected) $=\bar{\phi}\left[0.7760+0.01800^{2}\right]$ if $4.2 \leq \mathrm{z}<12$

$\sigma($ conrected $)=0.785 \overline{Q Q \beta} \quad$ for $2<x \leq 4.2$

Equations (4), (6), end (7) apply for pesir production in the field of the nucleus and do not include the pair production in the fleld of the electrons or the effects of screening.

The pair production in'the fleld of the nucleus as determined from Eqg. (6) and (7) plus the patr produetion in the field of the electrons as given by Borselinoll is presented in Table 1 for several elements.

A comparison of Eqs. (6) and (7) against the experimental data of Rosenblum et $a,^{1}$ Dayton, ${ }^{7}$ Jaeger et al, ${ }^{4,5,6}$ and Colgate ${ }^{12}$ is glven in FIga 1 through 3 .

I1. A. Borsellino, Muovo eimento, 4, 112 (1947).

12. S. A. Colgate, Phys. Rev. 87, $\overline{59 e}$ (195e). 


\section{Table 1. Pair Production Cross sections (barns per atom)}

\begin{tabular}{lccccccc}
\hline $\mathrm{Z}$ & 1 & 4 & 6 & 7 & 8 & 11 & 13 \\
\hline $\begin{array}{c}\mathrm{E} \\
\text { (Mev) }\end{array}$ & $\mathrm{B}$ & $\mathrm{Be}$ & $\mathrm{C}$ & $\mathrm{N}$ & 0 & $\mathrm{Na}$ & $\mathrm{Al}$ \\
\hline 1.1 & $4.48 \times 10^{-7}$ & $7.19 \times 10^{-6}$ & $1.62 \times 10^{-5}$ & $2.22 \times 10^{-5}$ & $2.91 \times 10^{-5}$ & $5.56 \times 10^{-5}$ & $7.84 \times 10^{-5}$ \\
1.2 & $4.17 \times 10^{-6}$ & $6.70 \times 10^{-5}$ & $1.51 \times 10^{-4}$ & $2.06 \times 10^{-4}$ & $2.70 \times 10^{-4}$ & $5.16 \times 10^{-4}$ & $7.27 \times 10^{-4}$ \\
1.3 & $1.28 \times 10^{-5}$ & $2.05 \times 10^{-4}$ & $4.63 \times 10^{-4}$ & $6.31 \times 10^{-4}$ & $8.26 \times 10^{-4}$ & $1.58 \times 10^{-3}$ & $2.22 \times 10^{-3}$ \\
1.4 & $2.63 \times 10^{-5}$ & $4.22 \times 10^{-4}$ & $9.51 \times 10^{-4}$ & $1.30 \times 10^{-3}$ & $1.70 \times 10^{-3}$ & $3.24 \times 10^{-3}$ & $4.55 \times 10^{-3}$ \\
1.5 & $4.42 \times 10^{-5}$ & $7.08 \times 10^{-4}$ & $1.60 \times 10^{-3}$ & $2.18 \times 10^{-3}$ & $2.85 \times 10^{-3}$ & $5.43 \times 10^{-3}$ & $7.63 \times 10^{-3}$ \\
1.75 & $1.03 \times 20^{-4}$ & $1.66 \times 10^{-3}$ & $3.73 \times 10^{-3}$ & $5.09 \times 10^{-3}$ & $6.66 \times 10^{-3}$ & $1.27 \times 10^{-2}$ & $1.78 \times 10^{-2}$ \\
2 & $1.76 \times 10^{-4}$ & $2.82 \times 10^{-3}$ & $6.35 \times 10^{-3}$ & $8.65 \times 10^{-3}$ & $1.13 \times 10^{-2}$ & $2.15 \times 10^{-2}$ & $3.01 \times 10^{-2}$ \\
3 & $5.60 \times 10^{-4}$ & $8.31 \times 10^{-3}$ & $1.85 \times 10^{-2}$ & $2.52 \times 10^{-2}$ & $3.28 \times 10^{-2}$ & $6.20 \times 10^{-2}$ & $8.65 \times 10^{-2}$ \\
4 & $1.00 \times 10^{-3}$ & $1.39 \times 10^{-2}$ & $3.07 \times 10^{-2}$ & $4.16 \times 10^{-2}$ & $5.41 \times 10^{-2}$ & $1.02 \times 10^{-1}$ & $3.41 \times 10^{-1}$ \\
5 & $1.44 \times 10^{-3}$ & $1.90 \times 10^{-2}$ & $4.28 \times 10^{-2}$ & $5.64 \times 10^{-2}$ & $7.33 \times 10^{-2}$ & $1.37 \times 10^{-1}$ & $1.90 \times 10^{-1}$ \\
& & & & & & & \\
\hline
\end{tabular}


Table 1 (cont.)

\begin{tabular}{|c|c|c|c|c|c|c|c|}
\hline$z$ & 14 & 18 & 20 & 26 & 29 & 42 & 50 \\
\hline$\underset{(H=V)}{E}$ & $\$ 1$ & A & $\mathrm{Ca}$ & $\mathrm{Te}$ & $a_{1}$ & Ho & Sn \\
\hline 1.1 & $9.14 \times 10^{-5}$ & $1.55 \times 10^{-4}$ & $2.94 \times 10^{-4}$ & $3.46 \times 10^{-4}$ & $4.43 \times 10^{-4}$ & $1.08 \times 10^{-3}$ & $2.71 \times 10^{-3}$ \\
\hline 1.2 & $8.48 \times 10^{-4}$ & $1.43 \times 10^{-3}$ & $1.79 \times 10^{-3}$ & $3.18 \times 10^{-3}$ & $4.06 \times 10^{-3}$ & $9.77 \times 10^{-3}$ & $1.53 \times 10^{-2}$ \\
\hline 1.3 & $2.59 \times 10^{-3}$ & $4.36 \times 10^{-3}$ & $5.45 \times 10^{-3}$ & $9.60 \times 10^{-3}$ & $1.22 \times 10^{-2}$ & $2.91 \times 10^{-2}$ & $4.51 \times 10^{-2}$ \\
\hline 1.4 & $5.30 \times 20^{-3}$ & $8.92 \times 10^{-3}$ & $1.13 \times 10^{-2}$ & $1.95 \times 10^{-2}$ & $2.48 \times 10^{-2}$ & $5.83 \times 10^{-2}$ & $8.98 \times 10^{-2}$ \\
\hline 1.5 & $8.88 \times 10^{-3}$ & $1.49 \times 20^{-2}$ & $1.86 \times 10^{-2}$ & $3.25 \times 10^{-2}$ & $4.12 \times 10^{-2}$ & $9.57 \times 10^{-2}$ & $1.46 \times 10^{-1}$ \\
\hline 1.75 & $2,06 \times 10^{-2}$ & $3.45 \times 10^{-2}$ & $4.29 \times 10^{-2}$ & $7.44 \times 10^{-2}$ & $9.40 \times 10^{-2}$ & $2.15 \times 10^{-1}$ & $3.21 \times 10^{-1}$ \\
\hline 2 & $3.49 \times 10^{-2}$ & $5.85 \times 10^{-2}$ & $7.23 \times 10^{-2}$ & $1.25 \times 10^{-1}$ & $1.57 \times 10^{-1}$ & $3.49 \times 10^{-1}$ & $5.18 \times 10^{-1}$ \\
\hline 3 & $1.00 \times 10^{-1}$ & $1.66 \times 10^{-3}$ & $2.05 \times 10^{-1}$ & $3.47 \times 10^{-1}$ & $4.35 \times 10^{-1}$ & $9.28 \times 10^{-1}$ & 1.33 \\
\hline 4 & $1.64 \times 10^{-1}$ & $2.70 \times 10^{-1}$ & $3.34 \times 10^{-1}$ & $5.63 \times 10^{-1}$ & $7.00 \times 10^{-1}$ & 1.48 & 2.10 \\
\hline 5 & $2.21 \times 10^{-1}$ & $3.63 \times 10^{-1}$ & $4.48 \times 10^{-1}$ & $7.55 \times 10^{-1}$ & $9.38 \times 10^{-1}$ & 1.96 & 2.75 \\
\hline
\end{tabular}




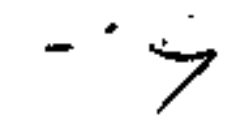

Pable 1 (cont.)

\begin{tabular}{|c|c|c|c|c|c|c|c|c|}
\hline$z$ & 53 & 7 & 4 & 78 & 82 & & 5 & 2 \\
\hline$\underset{(\text { Hev }}{\mathbf{E}}$ & I & & $\mathbf{W}$ & Pt & Po & & & $\mathbf{U}$ \\
\hline 1.1 & $2,00 \times 10^{-3}$ & 5.27 & $x 10^{-3}$ & $6.20 \times 10^{-3}$ & $7.25 x$ & $10^{-3}$ & 1.05 & $x 10^{-2}$ \\
\hline 1.2 & $1.78 \times 10^{-2}$ & 4.61 & $x 10^{-2}$ & $5.41 \times 10^{-2}$ & $6.31 \mathrm{x}$ & $10^{-2}$ & 9.09 & $\times 10^{-2}$ \\
\hline 1.3 & $5.25 \times 10^{-2}$ & 1.33 & $x \quad 10=-1$ & $1.56 \times 10^{-1}$ & $1.81 \mathrm{x}$ & $10^{-1}$ & 2.59 & $\times 10^{-1}$ \\
\hline 2.4 & $1.04 \times 10^{-1}$ & 2.59 & $x 10^{-1}$ & $3.02 \times 10^{-1}$ & $3.51 \times$ & $10^{-1}$ & 4.98 & $\times 10^{-1}$ \\
\hline 1.5 & $1.69 \times 10^{-1}$ & 4.14 & $\times 10^{-1}$ & $4.81 \times 10^{-1}$ & $5.56 x$ & $10^{-1}$ & 7.84 & $\times 10^{-1}$ \\
\hline 1.75 & $3.69 \times 1.0^{-1}$ & 8.64 & $\times 10^{-1}$ & $9.97 \times 10^{-1}$ & 1.14 & $\ldots$ & 1.59 & $-\infty$ \\
\hline 2 & $5.93 \times 10^{-1}$ & 1.34 & --- & 1.53 & 1.75 & --- & 2.39 & $=--$ \\
\hline 3 & $1.51=$ & 3.10 & :ne & 3.48 & 3.89 & --- & 5.06 & --- \\
\hline 4 & 2.36 & 4.67 & $=-1$ & 5.21 & 5.78 & $-\infty$ & 7.36 & 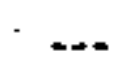 \\
\hline 5 & 3.10 & 6.08 & -- & 6.75 & 7.49 & --- & 9.42 & - \\
\hline
\end{tabular}




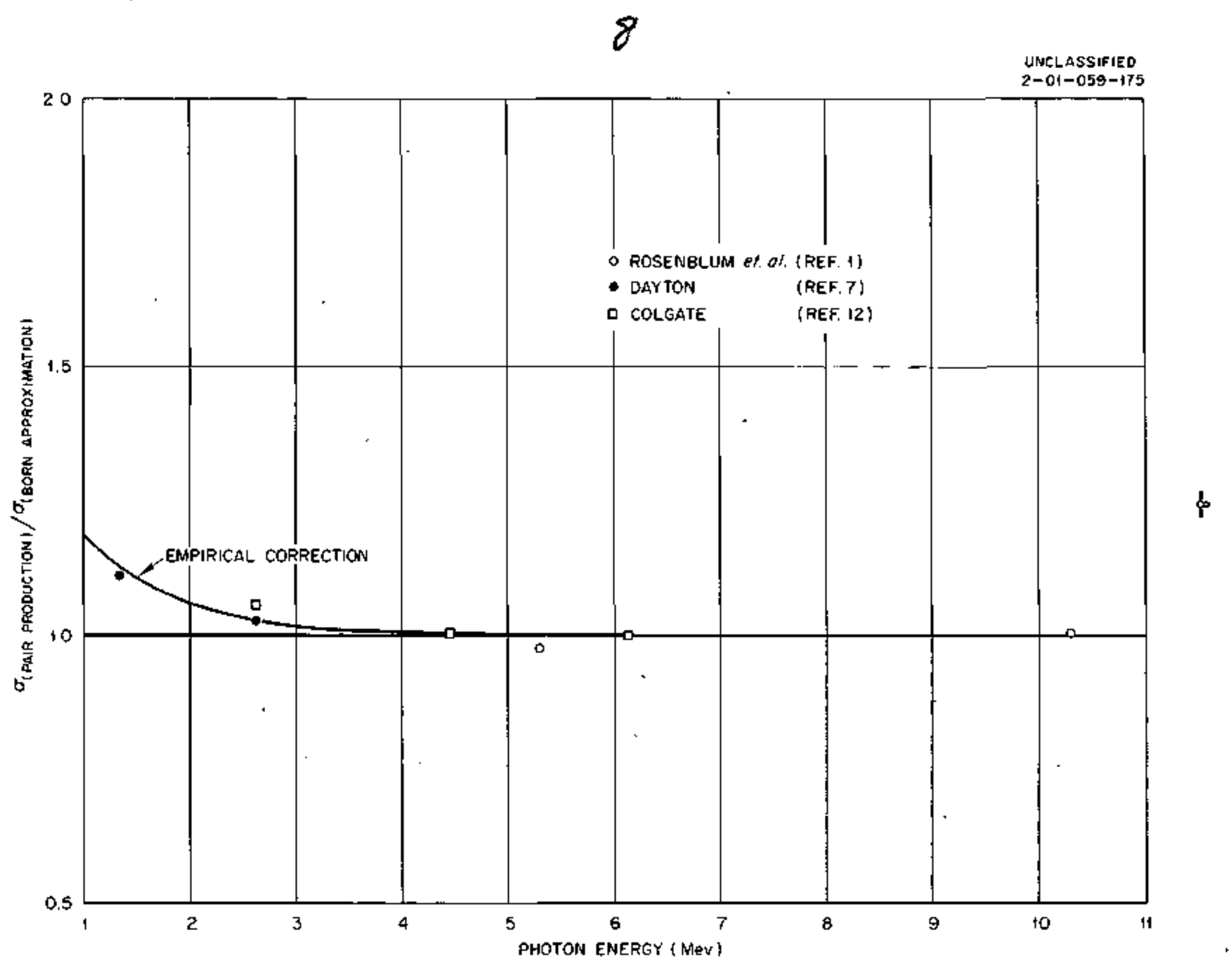

Fig. I. Comparison of Experimental and Calculated Pair Production in the Fieid of the Nucleus for Copper $\{Z=29\}$. 
10

UNCLASSIFIED

$v$
$i$
2

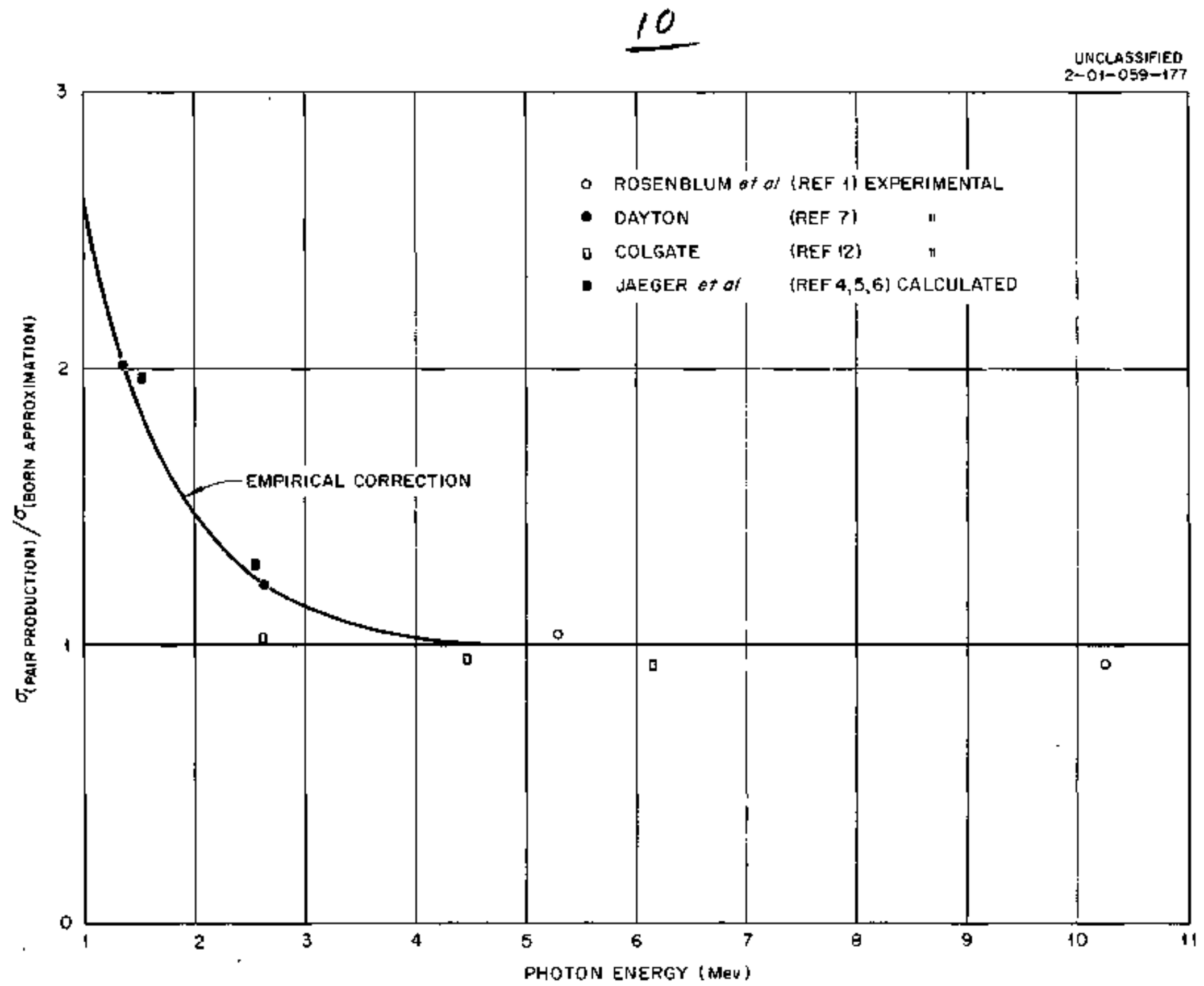

点

Fig 3. Comparison of Experimental and Calculated Pair Production in the Field of the Nucleus for Lead $(Z=82)$. 


\section{UMELASSEIFED}

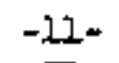

Values of the pasr-production cross section above the range of application of $\mathrm{Eq}$. (7) can be obtalned from the tables provtded by hitte. 13

13. G. R. White, X-Ray Attenuntion Coefficients (Nationai Bureau of Standards report) report nomber NiBS-1003 (1952).

\section{UHELASSFIED}

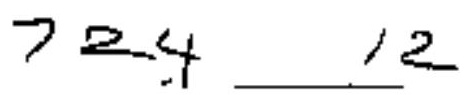


$0-11$

$+$

n

,
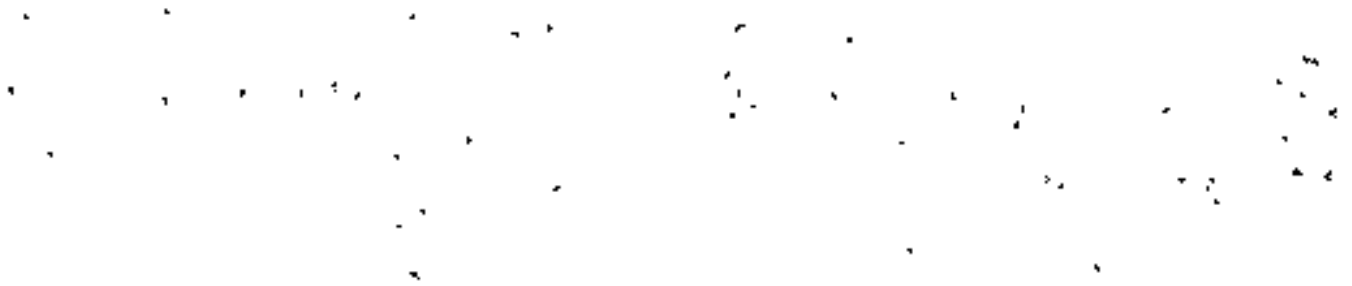

I':
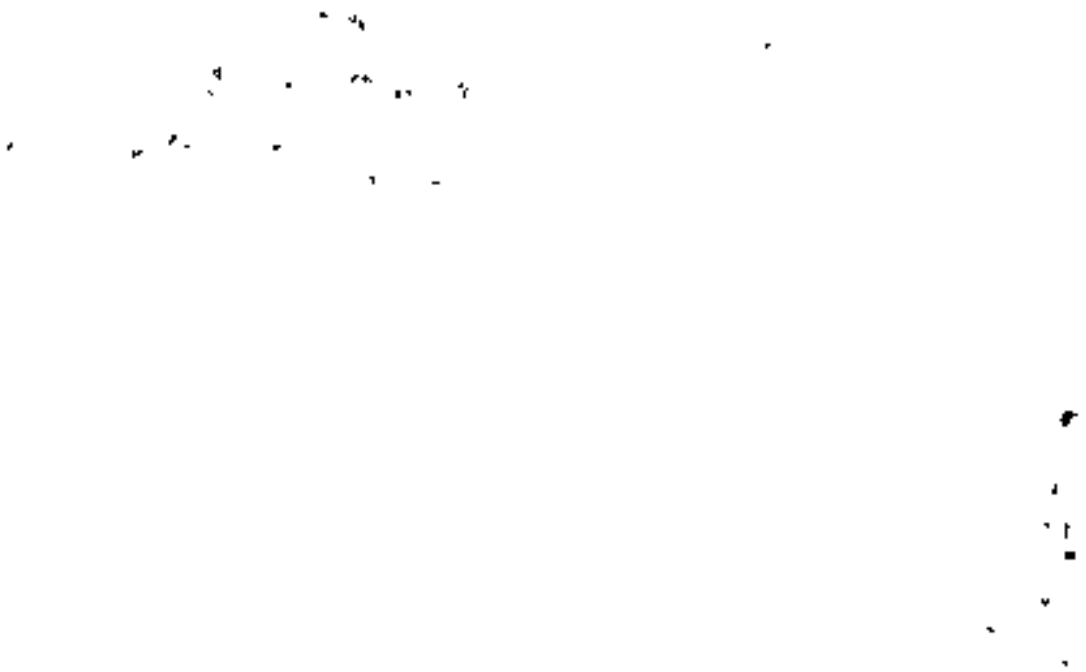